\title{
Risk Factors for Early Syphilis Among Gay and Bisexual Men Seen in an STD Clinic: San Francisco, 2002-2003
}

\author{
WILLIAM WONG, MD, ${ }^{*}$ JANICE K. CHAW, MPH, $†$ CHARLOTTE K. KENT, MPH, $†$ AND \\ JEFFREY D. KLAUSNER, MD, MPH†‡
}

\begin{abstract}
Background: Substantial increases in syphilis among gay and bisexual men have been reported in San Francisco.

Goal: To identify risk factors for early syphilis infection among gay and bisexual men attending the San Francisco municipal STD clinic (City Clinic).

Study: Cross-sectional, self-administered, behavioral survey of gay and bisexual men attending City Clinic between November 2002 and March 2003 linked with electronic medical record data.

Results: Among 1318 gay and bisexual men surveyed, $53(4.0 \%)$ were diagnosed with early syphilis. The final multivariate model included nonwhite race $(\mathrm{OR}=\mathbf{2 . 1}[1.1-4.4]), \mathrm{HIV}$-infection $(\mathrm{OR}=3.9$ [2.0-7.7]), using both methamphetamine and sildenafil $\left(\right.$ Viagra $\left.^{\circledR}\right)(\mathrm{OR}=6.2[2.6-$ 14.9]), using methamphetamine without sildenafil $(\mathrm{OR}=3.2[1.3-7.6])$, using sildenafil without methamphetamines $(O R=0.9[0.3-2.9])$, stronger gay community affiliation $(\mathrm{OR}=2.3[1.2-4.6])$, and having recent Internet partners $(\mathrm{OR}=\mathbf{2 . 1}[1.0-4.3])$.

Conclusions: Syphilis prevention efforts should address methamphetamine and sildenafil use among gay and bisexual men and require strong and substantive involvement with the gay community to address syphilis in San Francisco.
\end{abstract}

SINCE THE LATE 1990s, substantial increases in syphilis have been reported in San Francisco and other metropolitan areas across the United States, with increases noted among men who have sex with men (MSM). ${ }^{1-5}$ In San Francisco, there were 41 cases of early syphilis reported to the health department in 1998 and 525 cases reported in 2003, representing almost a 12-fold increase. Between 1999 and 2003, more than 85\% of early syphilis cases in San Francisco occurred among MSM, the majority of whom were infected with the human immunodeficiency virus (HIV). ${ }^{6,7}$ Since syphilis infection can facilitate both the transmission and acquisition of HIV infection, effective integrated STD and HIV prevention programs are needed to address the parallel epidemics of syphilis and HIV among MSM. ${ }^{8}$

Staff at City Clinic, the municipal STD clinic of the San Francisco Department of Public Health, provide care to clients who

The authors thank the staff of San Francisco City Clinic and STD Prevention and Control Services, especially Toni Butler, Larry Hanbrook, Robert Kohn MPH, Armando Litiatco, Kate Scott, MPH, Wendy Wolf, MPA, Registration Team, Clinicians, and members of the Syphilis Elimination Team. Special thanks go to Leila Alpers, MD, of University of California, San Francisco.

Correspondence: William Wong, MD, Medical Director, STD/HIV Prevention and Care Programs, Chicago Department of Public Health, $31^{\text {st }}$ Street Specialty Clinic, 530 East $31^{\text {st }}$ Street, Chicago, IL 60616. E-mail: wong_will@cdph.org.

Received for publication December 7, 2004, and accepted April 6, 2004.
From the *STD/HIV Prevention and Care Programs, Chicago Department of Public Health, Chicago, Illinois; TSTD Prevention and Control Services, San Francisco Department of Public Health, San Francisco, California; and the $¥$ Department of Medicine, University of California-San Francisco

make over 21,000 patient visits per year; approximately half of all visits are by MSM. ${ }^{7}$ Clinicians diagnose more than one third of early syphilis cases reported in the city annually. ${ }^{7}$ Because large numbers of early syphilis cases are diagnosed at City Clinic and because a high proportion of visits was by MSM, we conducted a cross-sectional study to identify risk factors for early syphilis infection among MSM attending City Clinic. Improved, targeted syphilis prevention programs then can be developed.

\section{Methods}

A convenience sample of self-identified gay and bisexual men attending City Clinic from November 2002 through March 2003 was asked to complete a self-administered survey while waiting to be seen. The survey consisted of 42 items that included demographic information, self-reported HIV status, sexual behavior, and recreational drugs, including sildenafil (Viagra ${ }^{\circledR}$ ) (Pfizer, New York, NY), used during any sexual encounter in the previous 4 weeks. The survey instrument was piloted and revised before implementation. Staff obtained verbal consent from participants before survey administration. This study was conducted as a part of the public health response to syphilis in San Francisco and was classified as nonresearch, in accordance with the human experimentation guidelines of the US Department of Health and Human Services.

To assess the level of identification with the gay community among participants, we reviewed the pertinent literature 9,10 and developed an index to measure the degree of affiliation with the gay community. This index consisted of 5 items that assessed personal identification with the gay community and with other gay or bisexual men, membership in gay community organizations, and reading gay community publications such as newspapers or magazines. Responses to these items were scored, with a maximum index of 25 points. To distinguish between high and low degrees of community affiliation among participants, an index cutoff value was determined by the median scores of respondents. High affiliation was defined by scores of 21 points or greater, and low affiliation was defined by scores of less than 20 . To assess the level of depressed mood among participants in the 4 weeks before the initial visit, we adapted scales of psychological well-being. ${ }^{11}$ 
This brief validated inventory consisted of 3 items that assessed symptoms of dysphoria, depressive mood, and hopelessness on a 6-point scale. Condom use data were not interpretable due to the incomplete collection of the information.

Data from the survey were linked with clinical and laboratory data from the electronic medical record using a unique patient identification number. Clinicians diagnosed early syphilis infection by clinical examination and serological evaluation using the rapid plasmid reagin, Venereal Disease Research Laboratory test, and $T$ pallidum particle agglutination test, and by dark-field microscopy performed on syphilis lesions. Early syphilis includes primary, secondary, and early latent stages of disease. Syphilis cases were staged and classified according to Centers for Disease Control and Prevention (CDC) clinical case definitions for early syphilis. ${ }^{12}$ Cases were staged as early latent syphilis when initial infection occurred within the previous 12 months in an infected person without any signs or symptoms of syphilis based on 1 or more of the following criteria: documented seroconversion or fourfold or greater increase in titer of a nontreponemal test during the previous 12 months, a history of symptoms consistent with primary or secondary syphilis during the previous 12 months, a history of sexual exposure to a partner who had confirmed or probable primary or secondary syphilis or probable early latent syphilis (documented independently as duration $<1$ year), or reactive nontreponemal and treponemal tests from a person whose only possible exposure occurred within the preceding 12 months.

With an early syphilis prevalence of 3\% among MSM seen at City Clinic, we estimated a priori that we would need a sample size of 1500 to observe a twofold difference between syphilis and nonsyphilis cases with $95 \%$ confidence. Survey data were entered into EpiInfo version 6.04 (CDC) by a trained data entry clerk. We conducted univariate, bivariate, stratified, and multivariate logistic regression analyses using SAS version 8e (SAS Institute, Cary, NC). Factors that were associated with early syphilis infection in the univariate analysis at $P$ values of $\leq 0.2$ and known confounders such as age and number of sex partners were entered into the multivariate analysis. Using a backward variable selection method, known confounders and variables that remained associated with early syphilis at $P<0.05$ significance level were retained in the multivariate model.

\section{Results}

From November 2002 to March 2003, 2107 gay and bisexual men were seen at City Clinic, of whom 1318 (63\%) completed the study survey. Most participants self-identified as gay (89\%), and $11 \%$ identified as bisexual. The median age was 36 years (range $18-74)$. The majority were white $(64 \%)$ and educated; $30 \%$ of participants reported having attended some college or technical school without graduating, and $60 \%$ reported having completed college or graduate school. The majority $(80 \%)$ of participants knew their HIV status at the time of the survey; $18 \%$ reported being HIV-positive. One-third (34\%) of participants reported having an annual income between $\$ 20,000$ and $\$ 49,000,42 \%$ reported earning less than $\$ 20,000$ per year, and $24 \%$ reported an annual income of $\$ 50,000$ or more. Almost three-quarters (74\%) resided in San Francisco for more than 2 years. Participants reported having had a median of 5.0 (range $0-100$ ) male sexual partners in the 4 weeks before their clinic visit.

Reasons cited for nonparticipation in the study by clinic patients included unwillingness to complete the survey or to take part in the study and not being offered the survey instrument. The demographic characteristics of the gay and bisexual men seen at the STD clinic during the study period who did not complete a survey $(\mathrm{n}=789)$ were similar to gay and bisexual men who took the survey $(\mathrm{n}=1318)$ in age (mean age: 37.1 vs. 36.0 years; $P=0.41)$ and race/ethnicity (white race: $62 \%$ vs. $64 \% ; P=0.34$ ). Annual income was higher among nonparticipants than participants (annual income $>\$ 30,000$ : $69 \%$ vs. $45 \% ; P<0.0001$ ). Early syphilis infection was diagnosed in $28(3.5 \%)$ nonparticipants.

Overall, early syphilis infection was diagnosed in $4 \%$ (53 of 1318 ) of those gay and bisexual men surveyed. (Table 1) Of the 53 early syphilis cases identified, $11(20.8 \%)$ were primary, 27 $(50.9 \%)$ were secondary, and $15(28.3 \%)$ were classified as early latent syphilis. In bivariate analysis, age and race/ethnicity were similar among men who were and were not diagnosed with syphilis. HIV-infected participants were more than 5 times as likely to have syphilis compared to HIV-negative men and men with unknown HIV status. Participants with high scores on the community affiliation index were more than 2 times as likely to be diagnosed with early syphilis compared to those who scored lower. Depressed mood was not associated with syphilis. Men who reported having 6 or more male partners were over 3 times more likely to be diagnosed with early syphilis, while men who reported having 2 to 5 male partners were more than 2 times more likely to be diagnosed with early syphilis, than men who reported having 1 or no male partners in the previous 4 weeks.

In bivariate analyses, men who reported using both methamphetamines and sildenafil while having sex in the prior 4 weeks were over 7 times more likely to have early syphilis than men who did not use these drugs. In contrast, men who used methamphetamines without sildenafil were more than 4 times as likely to have early syphilis compared to nonusers, and men who used sildenafil without methamphetamines were at similar risk for early syphilis than nonusers. Men who used other drugs in the 4 weeks before the clinic visit were more than twice as likely to be diagnosed with early syphilis compared to nonusers. Other drugs included cocaine, poppers, GHB, ecstasy, and ketamine used in the previous 4 weeks while having sex. Reported alcohol use appeared to have a modest protective effect. Men who used the Internet and those who used phone sex lines to meet sex partners in the 4 weeks before the clinic visit were over 2 times more likely to be diagnosed with early syphilis than men who did not use these venues. Adult bookstores, bars/clubs, circuit parties, sex clubs, bathhouses, parks and other public places were not significant in bivariate analyses.

The independent correlates for syphilis infection are also presented in Table 1. Nonwhite gay and bisexual men were more than twice as likely to have syphilis as white men, and HIV-infected men were almost 4 times more likely to be diagnosed with early syphilis than gay and bisexual men who were HIV-negative or whose HIV status was unknown. Men with high gay community affiliation indices had a twofold greater risk for early syphilis infection than men with low community affiliation. Men who used the combination of methamphetamines and sildenafil were more than 6 times more likely to have early syphilis infection compared to nonusers. Also, men who used any methamphetamines without sildenafil had a threefold greater risk for syphilis infection than nonusers. Of particular note, men who reported using sildenafil without methamphetamines were not at significant increased risk for syphilis infection than those who reported neither using sildenafil nor methamphetamine. Finally, gay and bisexual men who reported having met partners on the Internet in the 4 weeks before diagnosis were more than 2 times as likely as non-Internet users to be infected with early syphilis.

\section{Discussion}

We found that HIV infection, methamphetamine use especially with sildenafil, meeting recent sex partners on the Internet, non- 
TABLE 1. Bivariate and Multivariate Analyses of Risk Factors for Early Syphilis Infection Among Gay and Bisexual Men Seen in an STD Clinic: San Francisco, 2002-2003

\begin{tabular}{|c|c|c|c|c|c|c|}
\hline & \multicolumn{2}{|c|}{$\begin{array}{l}\text { Persons With } \\
\text { Early Syphilis } \\
\text { Diagnosis } \\
(n=53)\end{array}$} & \multicolumn{2}{|c|}{$\begin{array}{c}\text { Persons } \\
\text { Without Early } \\
\text { Syphilis } \\
\text { Diagnosis } \\
(\mathrm{n}=1265)\end{array}$} & \multirow{2}{*}{$\begin{array}{c}\begin{array}{c}\text { Bivariate } \\
\text { Odds Ratio }\end{array} \\
\text { OR }(95 \% \mathrm{Cl})\end{array}$} & \multirow{2}{*}{$\begin{array}{l}\text { Multivariate } \\
\text { Odds Ratio }\end{array}$} \\
\hline & $\mathrm{n}$ & $(\%)$ & $\mathrm{n}$ & $(\%)$ & & \\
\hline$\geq 35$ & 32 & (60) & 613 & (52) & Ref & Ref \\
\hline \multicolumn{7}{|l|}{ Race/ethnicity ( $n=1206)$} \\
\hline Nonwhite* & 21 & (40) & 419 & (36) & $1.2(0.6-2.1)$ & $2.1(1.1-4.4)$ \\
\hline White & 32 & (60) & 734 & (64) & Ref & Ref \\
\hline \multicolumn{7}{|l|}{ Sexual orientation $(n=1186)$} \\
\hline Gay & 50 & (94) & 1000 & (88) & $2.2(0.7-9.0)$ & - \\
\hline Bisexual & 3 & (6) & 133 & (22) & Ref & \\
\hline \multicolumn{7}{|l|}{ Education $(n=1193)$} \\
\hline High school diploma & 5 & (10) & 122 & (11) & Ref & \\
\hline \multicolumn{7}{|l|}{ Annual income $(n=1092)$} \\
\hline$\leq \$ 29,000$ & 27 & (56) & 572 & (55) & $1.1(0.6-2.0)$ & - \\
\hline$\geq \$ 30,000$ & 21 & (44) & 472 & (45) & Ref & \\
\hline \multicolumn{7}{|l|}{ Years living in San Francisco $(n=1225)$} \\
\hline$>2$ & 46 & (87) & 857 & (73) & $2.4(1.0-5.9)$ & - \\
\hline$\leq 1$ & 7 & (13) & 315 & (27) & Ref & \\
\hline \multicolumn{7}{|c|}{ Gay community affiliation index $\uparrow(n=1192)$} \\
\hline High & 37 & (70) & 551 & (52) & $2.5(1.3-4.7)$ & $2.3(1.2-4.6)$ \\
\hline Low & 16 & (30) & 588 & (48) & Ref & Ref \\
\hline \multicolumn{7}{|l|}{ Social supportł (n = 1184) } \\
\hline None & 4 & $(8)$ & 49 & (4) & $1.8(0.5-5.6)$ & - \\
\hline$\geq 1$ & 48 & (92) & 1083 & (96) & Ref & \\
\hline Yes & 14 & (38) & 74 & (8) & $7.2(3.3-15.3)$ & $6.2(2.6-14.9)$ \\
\hline No & 23 & (62) & 872 & (92) & Ref & Ref \\
\hline Any methamphetamine use without $s$ & & & & & & \\
\hline Yes & 12 & (35) & 103 & (11) & $4.4(2.0-9.6)$ & $3.2(1.3-7.6)$ \\
\hline No & 23 & (65) & 872 & (89) & Ref & Ref \\
\hline Any sildenafil use without methamph & & & & & & \\
\hline Yes & 4 & (15) & 123 & (12) & $1.2(0.4-3.8)$ & $0.9(0.3-2.9)$ \\
\hline No & 23 & (85) & 872 & (88) & Ref & Ref \\
\hline Other drugs used $\emptyset$ & & & & & & \\
\hline Yes & 26 & (49) & 363 & (31) & $2.2(1.2-3.9)$ & - \\
\hline No & 27 & (51) & 809 & (69) & Ref & \\
\hline Alcohol use & & & & & & \\
\hline Yes & 32 & $(60)$ & 847 & (74) & $0.5(0.3-1.0)$ & - \\
\hline No & 21 & (40) & 297 & (26) & Ref & \\
\hline Venues used to meet recent sex part & & & & & & \\
\hline Work or school & & & & & & \\
\hline Yes & 2 & (4) & 69 & (6) & $0.6(0.1-2.7)$ & - \\
\hline No & 51 & (96) & 1103 & (94) & Ref & \\
\hline Via mutual friends & & & & & & \\
\hline Yes & 10 & (19) & 163 & (14) & $1.4(0.7-3.0)$ & - \\
\hline No & 43 & (81) & 1009 & (86) & Ref & \\
\hline Phone sex lines & & & & & & \\
\hline Yes & 11 & (21) & 114 & (10) & $2.4(1.1-5.1)$ & - \\
\hline No & 42 & (79) & 1058 & (90) & Ref & \\
\hline
\end{tabular}




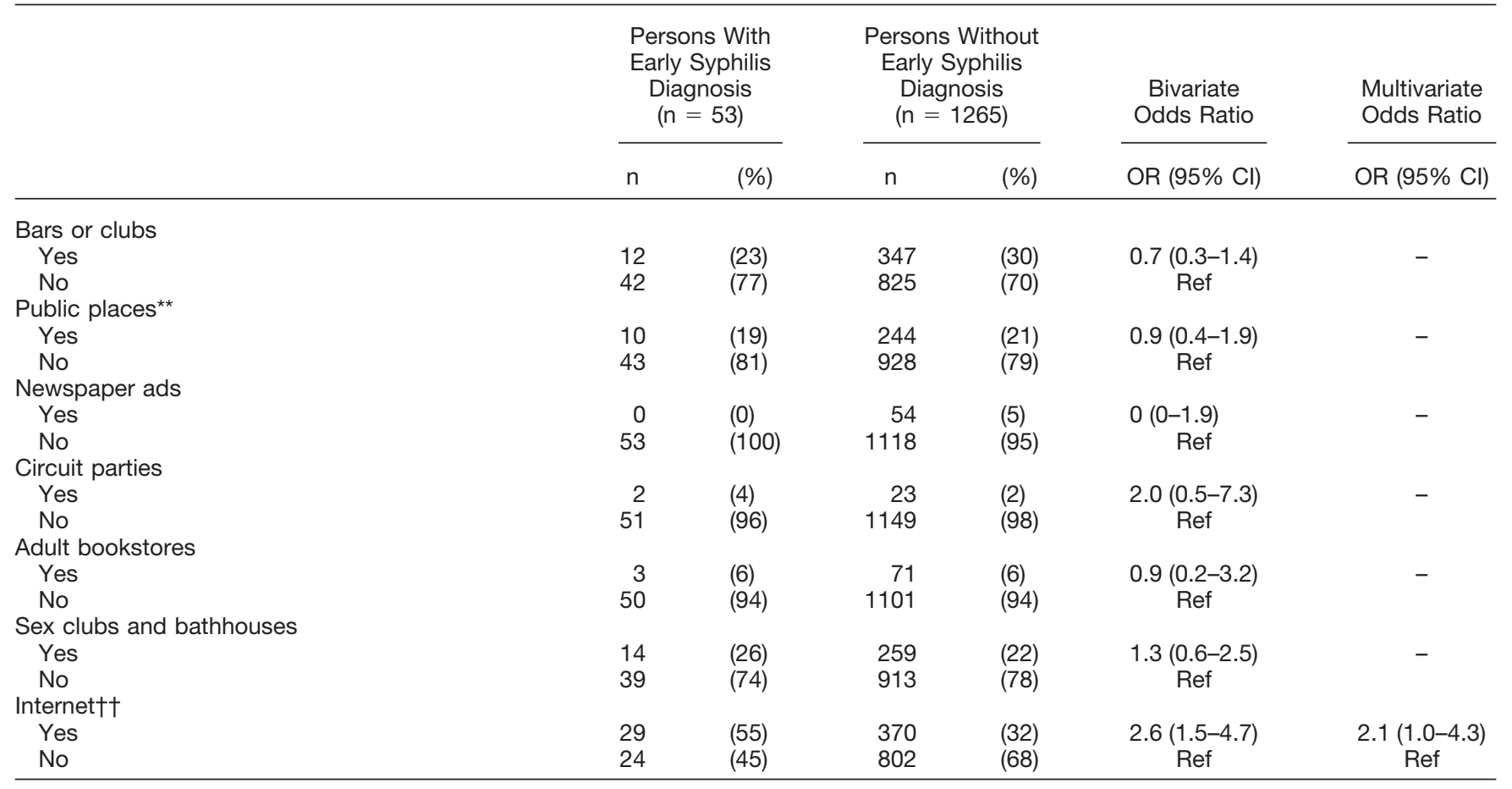

*Nonwhite race and ethnicity includes self-defined black, Asian Pacific Islander, Hispanic, and Native American identities.

† Gay community affiliation index: high affiliation $=21-25$ points; low affiliation $=1-20$ points.

¥ Social support measures indicate the self-reported number of people in one's life with whom one feels emotionally close and can share personal problems.

$\S$ Number of self-reported male partners in the previous 4 weeks prior to initial visit.

$\|$ Recent drug use in the previous 4 weeks used during sex.

I Other drugs includes cocaine, gabba hydroxybuterate (GHB), ecstasy (E), ketamine (Special K), nitrates (poppers), and heroin.

\# Venues used to meet sex partners in the previous 4 weeks.

${ }^{* *}$ Public places includes parks, rest areas, on the street, and alleys.

†† Internet use includes online chat rooms, postings, websites, and message boards.

white race, and stronger gay community affiliation were associated with an increased risk of early syphilis infection among gay and bisexual men seen at San Francisco City Clinic.

Clinical manifestations of syphilis are altered in HIV-infected persons who may present with multiple chancres in primary syphilis, overlapping clinical features of primary and secondary stages, higher syphilis serological titers at baseline, and slower serological declines following treatment. ${ }^{13,14}$ Syphilis infection can increase HIV viral load and decrease CD4 cell counts in HIV-infected persons and therefore may accelerate the progression of HIV disease and enhance the risk of HIV transmission. ${ }^{15,16}$ Because of the detrimental effects of syphilis in persons with HIV infection and because the majority of $\mathrm{HIV}$-infected persons receive routine HIV care in San Francisco, HIV care providers should have an important role in syphilis prevention efforts. In addition to syphilis screening, testing, and treatment services, HIV care providers can provide behavioral risk reduction counseling and health education for persons at risk for syphilis. Local health departments can implement health provider awareness campaigns with a special focus on HIV care providers by issuing medical alert letters, provider visitations, educational lectures, and focused communications such as correspondence letters and e-mail notices to increase the awareness of syphilis among providers and provide continuing medical education on syphilis symptom recognition and management recommendations.
Both methamphetamine and sildenafil use has been associated with higher risk sexual behaviors, including engaging in unprotected anal sex, having an increased number of sexual partners, and with the acquisition of sexually transmitted diseases, including HIV, among MSM in different settings. ${ }^{17-24}$ In addition, methamphetamine use has been associated with impaired adherence to antiretroviral medication regimens and increased HIV viral loads among HIV-positive active methamphetamine users, ${ }^{25,26}$ thereby potentially increasing HIV transmission risk in this population. We found that men who used methamphetamine without sildenafil were at increased risk for syphilis infection, whereas men who used sildenafil without methamphetamine were not at increased risk for syphilis infection. Furthermore, the combined use of methamphetamine with sildenafil substantially increased the risk for syphilis infection among gay and bisexual men in this study. This interaction between sildenafil and methamphetamine use may reflect the social context in which these substances are used and is consistent with reports of the use of sildenafil to counteract the erectile dysfunctional effects of methamphetamines, leading to higher-risk sexual behaviors that facilitate syphilis transmission. ${ }^{27}$ Because of the strong association between early syphilis and methamphetamine use, especially with sildenafil, substance-abuseprevention efforts should be integrated into broader STD and HIV control strategies. Several studies describe reductions in sexualrisk behaviors among gay and bisexual men following substance 
abuse treatment. ${ }^{28-30}$ Local health departments can collaborate with methamphetamine-abuse treatment programs to increase the awareness of syphilis among providers and clients and to encourage syphilis testing as a routine part of the treatment intake evaluation. Physicians can intervene by educating patients about sexually transmitted diseases in addition to providing general sex education and sexual risk reduction counseling for patients and partners before prescribing sildenafil. ${ }^{31}$ Public health leaders can educate health providers about STD and HIV counseling messages to share with patients when prescribing sildenafil and other drugs used to treat erectile dysfunction. Public health leaders can also work with the pharmaceutical industry to directly educate users of sildenafil about the risk of STD and HIV transmission associated with sexual-risk behaviors. ${ }^{32}$

The emergence of the Internet as a place where persons diagnosed with syphilis and other STDs meet sexual partners has challenged public health agencies to expand outreach and prevention efforts in this setting.6,33-37 In San Francisco, Internet-based prevention interventions have included the development of a website (www.sfcityclinic.org), the creation of internet links to syphilis testing services, individual outreach in Internet chat rooms and public message boards, health-promotional banner advertisements, the development of an e-mail listserv to distribute syphilis updates, the creation of an online syphilis-testing program (www.stdtest.org), and collaboration with officials at Gay.com to develop and implement "Ask Dr. K," an internet-based STD educational question and answer service. ${ }^{38-41}$ Because of the association between early syphilis and meeting sex partners online, Internetbased health promotion and disease prevention for MSM should continue, along with other syphilis-prevention activities.

Racial and ethnic disparities in syphilis rates continue to persist in the United States. ${ }^{42}$ Higher prevalence rates of HIV and STDs and differential sexual-risk behaviors among MSM of color compared to white MSM demonstrate that racial and ethnic disparities in health also exist among MSM. ${ }^{43,44}$ Racial and ethnic disparities may indicate markers for differences in sexual risk behaviors, socioeconomic status, sexual networks, social support, social disenfranchisement, and marginalization among MSM of color. ${ }^{45-47}$ The higher risk for syphilis among nonwhite gay and bisexual men suggests that continued efforts to prevent and control syphilis incidence in these populations are needed.

Finally, since we observed that gay and bisexual men with high levels of community affiliation were more likely to have syphilis than men with low levels of community affiliation, these data confirm the importance of collaborating with gay community organizations and media outlets, inclusive of gay communities of color, to address the syphilis epidemic in San Francisco. Public health departments can partner with gay community-based organizations including local gay community centers and HIV/AIDS service and prevention organizations. Public health departments should involve community-based organizations in planning syphilis-prevention activities through community collaboration and advisory committees. The San Francisco Department of Public Health has embraced an innovative social marketing campaign to reach gay and bisexual men at risk for syphilis (www. healthypenis2004.org) ${ }^{48,49}$ and has partnered with a local gay men's community health organization ${ }^{50}$ to increase community access to syphilis testing and treatment services in San Francisco. Involvement of the gay community potentially could have a tremendous impact in controlling the syphilis epidemic in San Francisco by reaching at-risk persons who would not ordinarily use STD services in traditional clinical settings.

There are several potential limitations to our findings. First, similar to case-control studies, this cross-sectional study design limits the inferences we can make on causality. However, an advantage of the cross-sectional design used in this investigation is that exposure and outcome were obtained simultaneously, and therefore potential recall bias is minimized. Second, these findings may not be generalizable to all gay and bisexual men in the community. Because gay and bisexual men who seek care at the municipal STD clinic most likely have higher-risk sexual behaviors than men seen outside of the public sector, these findings are probably more representative of gay and bisexual men with higherrisk sexual behaviors in San Francisco. Last, self-reported behavior is subject to bias that includes the underreporting of socially stigmatized behaviors, and therefore our findings might underestimate the level of risk for gay and bisexual men diagnosed with early syphilis.

More studies are needed to assess the increases in syphilis among MSM in local jurisdictions and nationally to further elucidate risk factors for infection. A better understanding of risk factors for syphilis infection among MSM can inform the public health programmatic response to more effectively target higherrisk subpopulations of MSM. Changes in the HIV epidemic and the emergence of the Internet have influenced sexual behaviors, partnering patterns, and sexual networks, in addition to the social and cultural factors that impact syphilis prevention and control efforts. Innovative programs, along with intervention evaluations, are needed to prevent and control syphilis in the community.

\section{References}

1. Williams LA, Klausner JD, Whittington WL, et al. Elimination and reintroduction of primary and secondary syphilis. Am J Public Health 1999; 89:1093-1097.

2. Chen JL, Kodagoda D, Lawrence AM, et al. Rapid public health interventions in response to an outbreak of syphilis in Los Angeles. Sex Transm Dis 2002; 29:277-284.

3. Centers for Disease Control and Prevention. Primary and secondary syphilis among men who have sex with men-New York City, 2001. MMWR. 2002; 51:853-856.

4. Centers for Disease Control and Prevention. Outbreak of syphilis among men who have sex with men-Southern California, 2000. MMWR Morb Mortal Wkly Rep 2001; 50:117-120.

5. D'Souza G, Lee JH, Paffel JM. Outbreak of syphilis among men who have sex with men in Houston, Texas. Sex Transm Dis 2003; 30:872-873.

6. Centers for Disease Control and Prevention. Internet use and early syphilis infection among men who have sex with men-San Francisco, California, 1999-2003. MMWR Morb Mortal Wkly Rep 2003; 52:1229-1232.

7. STD Prevention and Control Services, San Francisco Department of Public Health. Sexually transmitted Diseases annual summary, 2003. Available at: http://www.dph.sf.ca.us/Reports/STD/SFSTDAnnlSum2003.pdf.

8. Erbelding ED, Rompalo A. Changing epidemiology of syphilis and its persistent relationship with HIV. Curr Infect Dis Rep 2004; 6:135140

9. Stall R, Pollack L, Mills TC, et al. Use of antiretroviral therapies among HIV-infected men who have sex with men: a householdbased sample of 4 major American cities. Am J Public Health 2001; 91:767-773.

10. Meyer IH, Colten ME. Sampling gay men: random digit dialing versus sources in the gay community. J Homosex 1999; 37:99-110.

11. Dupuy HJ. The Psychological General Well-Being Index. In: Wenger NK, Mattson ME, Furberg CD, Elinson J, eds. Assessment of Quality of Life in Clinical Trials of Cardiovascular Therapies. New York: Le Jacq Publishing, 1984:184-188.

12. Centers for Disease Control and Prevention. Available at: http://www.cdc.gov/std.

13. Rompalo AM, Lawlor J, Seaman P, et al. Modification of syphilitic genital ulcer manifestations by coexistent HIV infection. Sex Transm Dis $2001 ; 28: 448-454$.

14. Rolfs RT, Joesoef MR, Hendershot EF, et al. A randomized trial of 
enhanced therapy for early syphilis in patients with and without human immunodeficiency virus infection: the Syphilis and HIV Study Group. N Engl J Med 1997; 337:307-314.

15. Buchacz K, Patel P, et al. Syphilis increases HIV viral load and decreases CD4 cell counts in HIV-infected patients with new syphilis infections AIDS 2004; 18:2075-2079.

16. Quinn TC, Wawer MJ, Sewankambo N, et al. Viral load and heterosexual transmissionof human immunodeficiency virus type 1: Rakai Project Study Group. N Engl J Med 2000; 342:921-929.

17. Lee SJ, Galanter M, Dermatis H, et al. Circuit parties and patterns of drug use in a subset of gay men. J Addict Dis 2003; 22:47-60.

18. Mansergh G, Shouse RL, Marks G, et al. Crystal use, Viagra use, sexual risk behaviors of men who have sex with men during a recent anal sex encounter. National STD Prevention Conference. Philadelphia, PA, March 8-11, 2004.

19. Mansergh G, Colfax GN, Marks G, et al. The Circuit Party Men's Health Survey: findings and implications for gay and bisexual men. Am J Public Health 2001; 91:953-958.

20. Colfax GN, Mansergh G, Guzman R, et al. Drug use and sexual risk behavior among gay and bisexual men who attend circuit parties: a venue-based comparison. J Acquir Immun Defic Syndr 2001; 28: 373-379.

21. Mitchell SJ, Wong W, Kent CK, et al. Methamphetamine use, sexual behavior, and sexually transmitted diseases among men who have sex with men seen in an STD clinic, San Francisco 2002-2003 National STD Prevention Conference. Philadelphia, PA, March $8-11,2004$.

22. Chu PL, McFarland W, Gibson S, et al. Viagra use in a communityrecruited sample of men who have sex with men, San Francisco. J Acquir Immun Defic Syndr 2003; 33:191-193.

23. Kim AA, Kent CK, Klausner JD. Increased risk of HIV and sexually transmitted disease transmission among gay or bisexual men who use Viagra, San Francisco 2000-2001. AIDS 2002; 16:1425-1428.

24. Buchacz K, McFarland W, et al. Amphetamine use is associated with increased HIV incidence among men who have sex with men (MSM) in San Francisco. AIDS. In press.

25. Ellis RJ, Childers ME, Cherner M, et al. Increased human immunodeficiency virus loads in active methamphetamine users are explained by reduced effectiveness of antiretroviral therapy. J Infect Dis 2003; 188:1820-1826.

26. Reback CJ, Larkins S, Shoptaw S. Methamphetamine abuse as a barrier to HIV medication adherence among gay and bisexual men. AIDS Care 2003; 15:775-785.

27. Halkitis PN, Parsons JT, Stirratt MJ. A double epidemic: crystal methamphetamine drug use in relation to HIV transmission among gay men. J Homosex 2001; 41:17-35.

28. Semple SJ, Patterson TL, Grant I. Motivations associated with methamphetamine use among HIV + men who have sex with men. J Subst Abuse Treat 2002; 22:149-156.

29. Reback CJ, Larkins S, Shoptaw S. Changes in the meaning of sexual risk behaviors among gay and bisexual male methamphetamine abusers before and after drug treatment. AIDS Behav 2004; 8:87-98.

30. Patterson TL, Semple SJ. Sexual risk reduction among HIV-positive drug-using men who have sex with men. J Urban Health 2003; 80(4 suppl 3):iii77-87.
31. Sadovsky R. Integrating erectile dysfunction treatment into primary care practice. Am J Med 2000; 109(suppl 9A):22S-28S

32. Chase M. A doctor fights for new warnings on Viagra labels. Wall Street Journal March 7, 2003:1

33. Centers for Disease Control and Prevention. Using the Internet for partner notification of sexually transmitted diseases-Los Angeles County, California, 2003. MMWR Morb Mortal Wkly Rep 2004; 53:129-131.

34. Klausner JD, Wolf W, Fischer-Ponce L, et al. Tracing a syphilis outbreak through cyberspace. JAMA. 2000; 284:447-449.

35. Ashton M, Sopwith W, Clark P, et al. An outbreak no longer: factors contributing to the return of syphilis in Greater Manchester. Sex Transm Infect 2003; 79:291-293.

36. Kim AA, Kent C, McFarland W, et al. Cruising on the internet highway. J AIDS 2001; 28:89-93.

37. McFarlane M, Bull SS, Rietmeijer CA. Young adults on the Internet: risk behaviors for sexually transmitted diseases and HIV-1. J Adolesc Health 2002; 31:11-16.

38. Klausner JD, Levine DK, et al. Internet-based site-specific interventions for syphilis prevention among gay and bisexual men. AIDS Care 2004; 16:964-970.

39. Levine DK, Scott KC, et al. Online syphilis testing-confidential and convenient. Sex Transm Dis 2005; 32:139-141.

40. Klausner JD. Websites and STD services. Sex Transm Dis 1999; 26:548.

41. Internet Sexuality Information Services, Inc. Available at: http://www. isis-inc.org. San Francisco, California.

42. Centers for Disease Control and Prevention. Primary and secondary syphilis-United States, 2002. MMWR Morb Mortal Wkly Rep 2003; 52:1117-1120

43. Harawa NT, Greenland S, Bingham TA, et al. Associations of race/ ethnicity with HIV prevalence and HIV-related behaviors among young men who have sex with men in 7 urban centers in the United States. J Acquir Immun Defic Syndr 2004; 35:526-536.

44. Torian LV, Makki HA, Menzies IB, et al. HIV infection in men who have sex with men, New York City Department of Health sexually transmitted disease clinics, 1990-1999: a decade of serosurveillance finds that racial disparities and associations between HIV and gonorrhea persist. Sex Transm Dis 2002; 29:73-78.

45. Kraft JM, Beeker C, Stokes JP, et al. Finding the "community" in community-level HIV/AIDS interventions: formative research with young African American men who have sex with men. Health Educ Behav 2000; 27:430-441.

46. Stokes JP, Peterson JL. Homophobia, self-esteem, and risk for HIV among African American men who have sex with men. AIDS Educ Prev 1998; 10:278-292.

47. Diaz RM. Latino Gay Men and HIV: Culture, Sexuality, and Risk Behavior. London: Routledge, 1988.

48. Montoya J, Kent C, et al. Social marketing campaign significantly associated with increases in syphilis testing among gay and bisexual men in San Francisco. Sex Transm Dis. In press.

49. Better World Advertising. Available at: http://www.socialmarketing.com. San Francisco, California.

50. Magnet. Available at: http://www.magnetsf.org. San Francisco, California. 